\title{
Molecular Dynamics and Physical Stability of Coamorphous Ezetimib and Indapamide Mixtures
}

J. Knapik ${ }^{* \dagger \ddagger}$, Z. Wojnarowska ${ }^{\dagger \ddagger}$, K. Grzybowska ${ }^{\dagger \ddagger}$, K. Jurkiewicz $^{\dagger \ddagger}$, L. Tajber $^{\S}$, and M. Paluch ${ }^{\dagger \ddagger}$

' Institute of Physics, University of Silesia, ul. Uniwersytecka 4, 40-007 Katowice, Poland

‡ SMCEBI, ul. 75 Pułku Piechoty 1a, 41-500 Chorzów, Poland

$\S$ School of Pharmacy and Pharmaceutical Sciences, Trinity College Dublin, College Green, Dublin 2, Ireland

E-mail: jknapik@us.edu.pl 


\section{Abstract}

Low physical stability is the main reason limiting the widespread use of amorphous pharmaceuticals. One approach to overcome this problem is to mix these drugs with various excipients. In this study coamorphous drug-drug compositions of different molar ratios of ezetimib and indapamid (i.e., EZB 10:1 IDP, EZB 5:1 IDP, EZB 2:1 IDP, EZB 1:1 IDP and EZB 1:2 IDP) were prepared and investigated using differential scanning calorimetry (DSC), broadband dielectric spectroscopy (BDS), and X-ray diffraction (XRD). Our studies have shown that the easily recrystallizing ezetimib drug can be significantly stabilized in its amorphous form by using even a small amount of indapamid (8.8 wt \%). DSC experiments indicate that the glass transition temperature $(\mathrm{Tg})$ of the tested mixtures changes with the drug concentration in accordance with the Gordon-Taylor equation. We also investigated the effect of indapamid on the molecular dynamics of the ezetimib. As a result it was found that, with increasing indapamid content, the molecular mobility of the binary drug-drug system is slowed down. Finally, using the XRD technique we examined the long-term physical stability of the investigated binary systems stored at room temperature. These measurements prove that low-molecular-weight compounds are able to significantly improve the physical stability of amorphous APIs.

Keywords: coamorphous mixture; drug-drug mixture; ezetimibe; glass transition; indapamide; molecular dynamics; physical stability 


\section{Introduction}

In recent years, amorphous drugs have become the subject of considerable interest due to their favorable properties such as higher apparent solubility, faster dissolution rate, and potentially better bioavailability when compared to their crystalline counterparts.(1-4) Although the benefits of amorphous pharmaceuticals are unquestionable, it should be pointed out that these materials are thermodynamically unstable. Consequently, during manufacturing or storage they may revert to the crystalline form and lose their superior properties.(5-7) Thus, to fully exploit the advantages given by drugs in the disordered state it is necessary to stabilize them in the amorphous form.(8)

Currently, the most effective strategy to suppress devitrification of amorphous active pharmaceutical ingredients (APIs) is to mix them with various excipients.(9-11) The mechanisms responsible for the stabilization of drugs in binary systems remain still unclear, however it is generally believed that the antiplasticizing effect exerted by an additive as well as the specific molecular interactions between drug and excipient may play crucial roles. $(12,13)$

Until recently, polymers with high glass transition temperature $\left(T_{\mathrm{g}}\right)$ were the most frequently recommended crystallization inhibitors.(14) However, due to the limited solubility of some drugs in polymeric matrix as well as other drawbacks of drug-polymer systems (e.g., difficulties in pulverization or poor compressibility), researchers are trying to find new, more effective stabilizers. $(15,16)$ Currently, binary amorphous mixtures comprising low-molecular-weight compounds instead of polymers have become the subject of significant interest.(17-19) Numerous experimental studies have consistently shown that small molecules such as saccharides or other APIs can improve the physical stability of easily recrystalling amorphous pharmaceuticals more effectively than polymers.(20-22) Alles $\varnothing$ et al. and Löbmann et al. reported that even very unstable drugs such as naproxen can be significantly stabilized by using another amorphous pharmaceutical: cimetidine or indomethacin.(23, 24) It should be pointed out that appropriate coamorphous combinations of two drugs can give a lot of benefits. Beyond improving water solubility and physical stability, the second API may improve the therapeutic effect and consequently bring economic advantages: cheaper production associated with smaller quantities of drugs and excipients, one production line, and one packing.

The present study deals with the coamorphous combination of two drugs, i.e., the cholesterollowering ezetimibe (EZB) and indapamid (IDP), that is commonly used for the treatment of hypertension. The binary amorphous EZB-IDP mixture is interesting for multiple reasons. First, such composition may provide a therapeutic advantage in the treatment of combined hypertension and hypercholesterolemia, as medical studies indicate that abnormal lipids and high blood pressure frequently coexist and both are the main risk factors for cardiovascular disease.(25-27) Second, both 
EZB and IDP belong to class II drugs according to the Biopharmaceutics Classification System (BCS), which means that their bioavailability is limited due to their low water solubility. $(28,29)$ Consequently, transformation of these APIs into their amorphous, more soluble forms is expected to enhance their bioavailability. Third, the dosing intervals are very similar for EZB and IDP, i.e., both drugs should be administered once daily, which justifies a need for preparing such binary mixtures.(30, 31) Ultimately, it is anticipated that a suitable stoichiometric combination of EZB with IDP will lead to a high physical stability, which will be beneficial from a manufacturing and storage perspective.

In the present study, binary amorphous mixtures of ezetimib and indapamid in various molar ratios were prepared by quench cooling from the melt. The physicochemical properties of the EZB-IDP compositions were studied by X-ray diffraction (XRD), differential scanning calorimetry (DSC), and FTIR (Fourier transform infrared spectroscopy). Furthermore, the molecular mobility that is generally considered as the main factor governing the physical stability of amorphous materials(32-34) was investigated for mentioned coamorphous drug-drug systems by means of broadband dielectric spectroscopy (BDS). From these results, one can answer the question: how does the IDP content affect the crystallization tendency of binary EZB-IDP mixture? Additionally, the long-term physical stability of EZB-IDP systems was studied by XRD.

\section{Experimental Methods}

Materials

Ezetimibe $\left(M_{\mathrm{w}}=409.4 \mathrm{~g} / \mathrm{mol}\right)$ and indapamide $\left(M_{\mathrm{w}}=365.8 \mathrm{~g} / \mathrm{mol}\right)$ drugs of purity greater than $99 \%$ were purchased from Polpharma (Starogard Gdański, Poland) and used as received. These pharmaceuticals are described chemically as (3R,4S)-1-(4-fluorophenyl)-3-[(3S)-3-(4-fluorophenyl)-3hydroxypropyl]-4-(4-hydroxyphenyl)azetidin-2-one and 4-chloro- $N$-[(2RS)-2-methyl-2,3-dihydro-1Hindol-1-yl)-3-sulfamoylbenzamide, respectively. Their chemical structures are presented in the inset of Figure 2.

Preparation of Binary Systems

The coamorphous mixtures of EZB and IDP drugs with various molar ratios EZB 10:1 IDP (8.8 wt \% of IDP), EZB 5:1 IDP (19.9 wt \% of IDP), EZB 2:1 IDP (31.4 wt \% of IDP), EZB 1:1 IDP (46.9 wt \% of IDP), and EZB 1:2 IDP (64.8 wt \% of IDP) were prepared by the quench cooling technique. In order to obtain the homogeneous binary systems prior to the quenching, we have prepared the physical mixtures of these compounds by gentle mixing in a mortar for $5 \mathrm{~min}$. After that we dried these mixtures for $10 \mathrm{~min}$ at $373 \mathrm{~K}$ to remove the water. This is because the IDP drug that was used in our experiment was hemihydrates. When the samples were dried, the crystalline mixtures were melted in aluminum 
dishes on a hot plate (CAT M. Zipperer GmbH H 17.5D) at $T=440 \mathrm{~K}$. Time of the sample melting was no longer than $2 \mathrm{~min}$. When the mixtures were fully melted, we vitrified them by fast transfer of the dish from the hot plate to a cold copper plate. The coamorphous binary mixtures of EZB and IDP obtained in the presented way were analyzed immediately after preparation to protect them from moisture.

Differential Scanning Calorimetry (DSC)

Thermodynamic properties of pure EZB, pure IDP, EZB 10:1 IDP, EZB 5:1 IDP, EZB 2:1 IDP, EZB 1:1 IDP, and EZB 1:2 IDP were examined using a Mettler-Toledo DSC 1 STAR ${ }^{\mathrm{e}}$ System. The measuring device was calibrated for temperature and enthalpy using zinc and indium standards. The instrument was equipped with an HSS8 ceramic sensor having 120 thermocouples and liquid nitrogen cooling station. Crystallization as well as melting points were determined as the onset of the peak, whereas the glass transition temperature was determined as the midpoint of the heat capacity increment. The samples were measured in an aluminum crucible $(40 \mu \mathrm{L})$. All measurements were carried out in the range from 298 to $450 \mathrm{~K}$ with a variety $-5 \mathrm{~K} / \mathrm{min}$ or $10 \mathrm{~K} / \mathrm{min}$ - of heating rates.

To obtain accurate temperature dependences of the heat capacity for pure amorphous EZB, IDP, and their binary mixtures, a stochastic temperature-modulated differential scanning calorimetry (TOPEM) method implemented by Mettler-Toledo TOPEM was employed. These measurements were performed in the temperature range from 300 to $390 \mathrm{~K}$ with a heating rate of $0.5 \mathrm{~K} / \mathrm{min}$.

Attenuated Total Reflection Fourier Transform Infrared Spectroscopy (ATR-FTIR)

Infrared spectra were recorded on a PerkinElmer Spectrum One FT-IR spectrometer and evaluated using Spectrum v5.0.1 software. Each spectrum was scanned in the range of $650-4000 \mathrm{~cm}^{-1}$ with a resolution of $4 \mathrm{~cm}^{-1}$, and a minimum of four scans were collected and averaged in order to obtain good quality spectra. The spectra were normalized and background corrected.

Broadband Dielectric Spectroscopy (BDS)

Dielectric measurements of pure EZB, pure IDP, EZB 10:1 IDP, EZB 5:1 IDP, EZB, EZB 1:1 IDP, and EZB 1:2 IDP were carried out using Novo-Control GMBH Alpha dielectric spectrometer, in the frequency range from $10^{-2} \mathrm{~Hz}$ to $10^{6} \mathrm{~Hz}$ at temperatures from 339 to $423 \mathrm{~K}$ with step of $2 \mathrm{~K}$. The temperature was controlled by a Quattro temperature controller with temperature stability better than $0.1 \mathrm{~K}$. Dielectric studies of all samples were performed immediately after fast cooling of the melt in a parallel-plate cell made of stainless steel (diameter $15 \mathrm{~mm}$ and a $0.1 \mathrm{~mm}$ gap with Teflon spacers).

X-ray Diffraction (XRD) 
The X-ray diffraction measurements were performed using a Rigaku-Denki D/MAX RAPID II-R diffractometer equipped with a rotating $\mathrm{Ag}$ anode $\left(\lambda_{\kappa \alpha}=0.5608 \AA\right)$, an incident beam (002) graphite monochromator, and an image plate in the Debye-Scherrer geometry as a detector. The X-ray beam width at the sample was $0.3 \mathrm{~mm}$. The investigated samples were placed inside glass capillaries with a diameter of $1.5 \mathrm{~mm}$ and wall thickness of $0.01 \mathrm{~mm}$. The measurements were carried out for the capillaries filled with samples and empty. The diffraction intensity for the empty capillary was then subtracted. The obtained two-dimensional diffraction patterns were converted into one-dimensional functions of intensity versus the scattering angle using suitable software.

\section{Thermal Properties of Amorphous Mixtures of Ezetimib and Indapamid Drugs}

The quench-cooled amorphous EZB has a glass transition temperature of $333.5 \mathrm{~K}$, when measured by using DSC with heating rate of $5 \mathrm{~K} / \mathrm{min}$. The DSC thermogram, obtained at this heating rate, exhibits an exothermic peak at $415 \mathrm{~K}$ corresponding to the sample cold crystallization (see Figure 1). This indicate that pure amorphous EZB reveals quite strong crystallization tendency above $T_{\mathrm{g}}$. The opposite behavior occurs for the pure amorphous IDP drug, that has $T_{\mathrm{g}}$ almost $40 \mathrm{~K}$ higher than that for EZB. In this case, recrystallization processes were not be observed both below and above the glass transition temperature even with a heating rate as slow as $1 \mathrm{~K} / \mathrm{min}$.

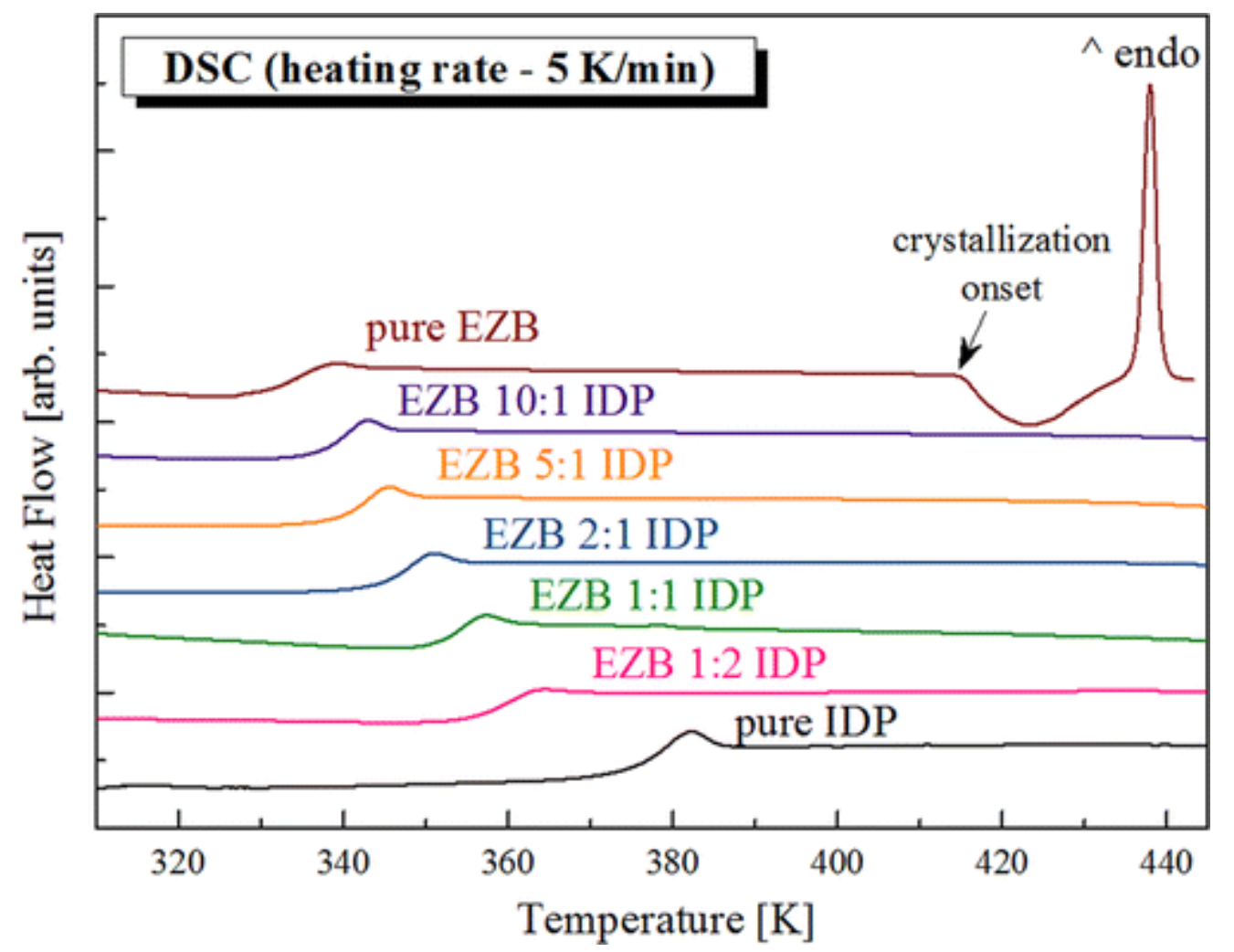

Figure 1. DSC thermograms of (heating rate $5 \mathrm{~K} / \mathrm{min}$ ): pure amorphous EZB drug, red line; binary amorphous EZB 10:1 IDP mixture, purple line; binary amorphous EZB 5:1 IDP mixture, orange line; 
binary amorphous EZB 2:1 IDP mixture, blue line; binary amorphous EZB 1:1 IDP mixture, green line; binary amorphous EZB 1:2 IDP mixture, pink line; and pure amorphous IDP drug, black line.

In order to find out how the thermal properties of the mentioned drugs will vary when the drugs are mixed together, five coamorphous mixtures containing various molar ratios of EZB and IDP (EZB-IDP: 10:1, 5:1, 2:1, 1:1, 1:2), have been measured using the DSC technique. All these measurements were carried out over the same temperature range, from 298 to $450 \mathrm{~K}$, and at two different heating rates: $5 \mathrm{~K} / \mathrm{min}$ and $10 \mathrm{~K} / \mathrm{min}$. As can be seen in Figure 1, the mixtures containing EZB and IDP are characterized by a single glass transition event which moves toward higher temperatures with IDP content.

These was no evidence of phase separation as there was only a single glass transition event for the binary mixtures. If components are not or are only partially miscible, the DSC curve of an amorphous composition should reveal two separate $T_{\mathrm{g}}$ : one for first component and one for the second component.(35) The values of $T_{\mathrm{g}}$ obtained using the DSC technique are collected in the Table 1.

Table 1. Comparison of the $T_{\mathrm{g}}$ and $\Delta C_{p}$ Values of Pure EZB and IDP Drugs and Their Binary Amorphous Mixtures at Molar Ratios 10:1, 5:1, 2:1, 1:1, 1:2

\begin{tabular}{|c|c|c|c|c|c|c|}
\hline \multirow[b]{2}{*}{$\begin{array}{c}\text { EZB-IDP } \\
\text { [molar } \\
\text { ratio] }\end{array}$} & \multirow[b]{2}{*}{$\begin{array}{c}\text { wt fraction } \\
\text { of IDP } \\
\text { [\%] }\end{array}$} & \multicolumn{3}{|c|}{$T_{\mathrm{g}}[\mathrm{K}]$} & \multirow[b]{2}{*}{$\begin{array}{l}\Delta C_{p} \\
{[\mathrm{~J} /} \\
\mathrm{gK}]\end{array}$} & \multirow{2}{*}{$\begin{array}{c}T_{\mathrm{g}}[\mathrm{K}] \\
\begin{array}{c}\text { predicted- } \\
\mathrm{GT}\end{array}\end{array}$} \\
\hline & & $\begin{array}{c}\text { DSC } \\
10 \\
\mathrm{~K} / \mathrm{min}\end{array}$ & $\begin{array}{l}\text { DSC } 5 \\
\mathrm{~K} / \mathrm{min}\end{array}$ & $\begin{array}{c}\text { TMDSC } \\
0.5 \\
\mathrm{~K} / \mathrm{min}\end{array}$ & & \\
\hline 1:0 & 0 & 336.4 & 333.5 & 334.8 & 0.47 & \\
\hline 10:1 & 8.8 & 340.6 & 338.8 & 337.9 & 0.47 & 337.9 \\
\hline $5: 1$ & 19.9 & 343.6 & 341.3 & 340.3 & 0.46 & 340.3 \\
\hline $2: 1$ & 31.4 & 348.1 & 345.9 & 345.5 & 0.46 & 346.5 \\
\hline 1:1 & 46.9 & 353.8 & 353.1 & 351.4 & 0.46 & 352.7 \\
\hline $1: 2$ & 64.8 & 360.4 & 358.8 & 359.2 & 0.42 & 360.0 \\
\hline $0: 1$ & 100 & 276.2 & 375.1 & 375.4 & 0.49 & \\
\hline
\end{tabular}

In Figure 1 we can also observed that all coamorphous compositions do not recrystallize when heated with a rate of $5 \mathrm{~K} / \mathrm{min}$. This indicates that even a small content of IDP may significantly suppress the crystallization tendency of EZB. There are two possible reasons for such behavior: an antiplasticizing effect exerted by the second drug or specific interactions between compounds, or eventually a combination of both these effects.(36) If the antiplastization effect is dominant, the changes of the glass transition temperatures with compound concentration should correlate with the theoretical dependence that was for the first time proposed by Gordon and Taylor: $(37,38)$

$T_{\mathrm{g}}=\frac{w_{1} T_{g 1}+K w_{2} T_{g 2}}{w_{1}+K w_{2}}$ 
where $w_{1}$ and $w_{2}$ are the weight fractions of each component, and $T_{\mathrm{g} 1}$ and $T_{\mathrm{g} 2}$ correspond to the glass transition temperature of each component. $T_{\mathrm{g}}$ is the glass transition temperature of the mixture, while $K$ is a measure of the interaction between the components, and it can be defined as follows:(39) $K \approx \frac{\Delta C_{p 2}}{\Delta C_{p 1}}(2)$

$\Delta C_{p}$ in eq 2 denotes the change in heat capacity at $T_{\mathrm{g}}$.

In order to check whether or not the antiplastization effect is the dominant mechanism responsible for better stability of EZB-IDP systems, the theoretical values of glass transition temperature for mixtures of various IDP content have been calculated by using eq 1 . The predicted values of $T_{\mathrm{g}}$ were subsequently compared with the experimentally determined data (see Figure 2). The values of $\Delta C_{p}$, that are required in eq 2 , as well as the values of the experimentally derived $T_{\mathrm{g}}$ were taken from stochastic temperature-modulated differential scanning calorimetry (TMDSC) measurements, where the heating rate was equal to $0.5 \mathrm{~K} / \mathrm{min}$.

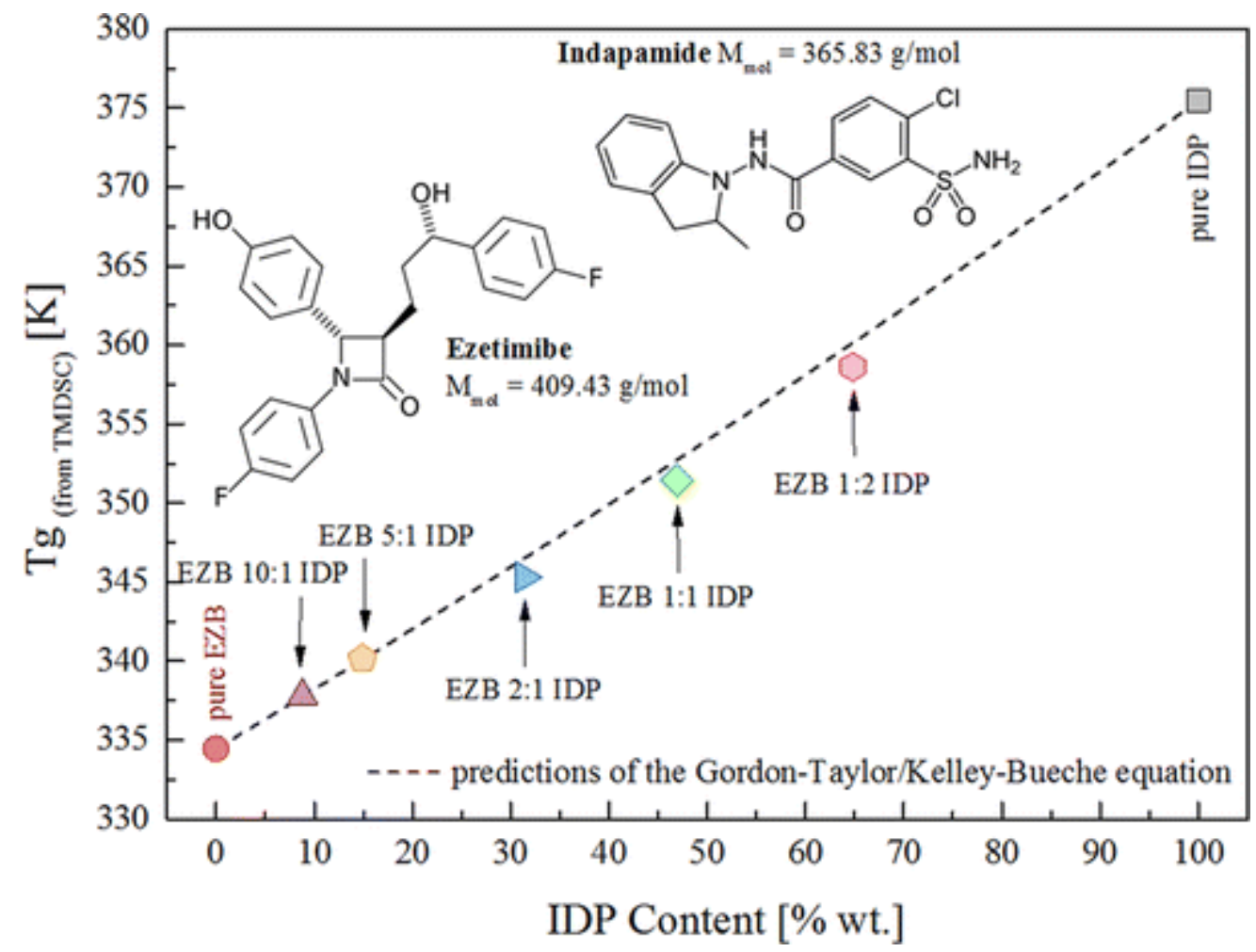

Figure 2. Glass transition temperatures of coamorphous EZB-IDP mixtures. The symbols correspond to the experimentally determined $T_{\mathrm{g}}$ values (heating rate $0.5 \mathrm{~K} / \mathrm{min}$ ), whereas the dashed line represents the prediction of the Gordon-Taylor/Kelley-Bueche equation calculated from the $T_{\mathrm{g}}$ values of the single EZB and IDP drugs. In the inset we present the chemical structures of EZB and IDP.

It can be clearly seen that $T_{\mathrm{g}}$ values grow continuously with increasing IDP content. At $8.8 \mathrm{wt} \%$ and $14.9 \mathrm{wt} \%$ of IDP the experimentally determined $T_{\mathrm{g}}$ values are in perfect agreement with those 
calculated theoretically. In the case of higher IDP content ( $\sim 30$ to $\sim 65 \mathrm{wt} \%$ of IDP) a slight negative deviation from the predicted glass transition temperatures can be observed. This deviation lies within the range 1-1.5 K. Because the difference between theoretically and experimentally determined $T_{\mathrm{g}}$ values is very small, one can expect that there are no significant molecular interactions between EZB and IDP. Thus, the enhancement of the physical stability of EZB drug is mainly due to the antiplasticizing effect. It is worth noting that small molecules like IDP are able to exert comparable or even better antiplasticizing effects than polymers, due to their high $T_{\mathrm{g}}$ values.

In order to confirm the absence of the specific chemical interactions between both mixed drugs we performed a series of FTIR experiments. As it can be seen in Figure 3 and Table 2, no considerable shifts of absorption bands associated with $\mathrm{H}$-bonds $(-\mathrm{C}=\mathrm{O}$ and $-\mathrm{S}=\mathrm{O})$ and $\pi-\pi$ interactions $(-\mathrm{C}=\mathrm{C}-$ of aromatic groups) are shown. This result indicates that EZB and IDP did not interact in the amorphous phase.

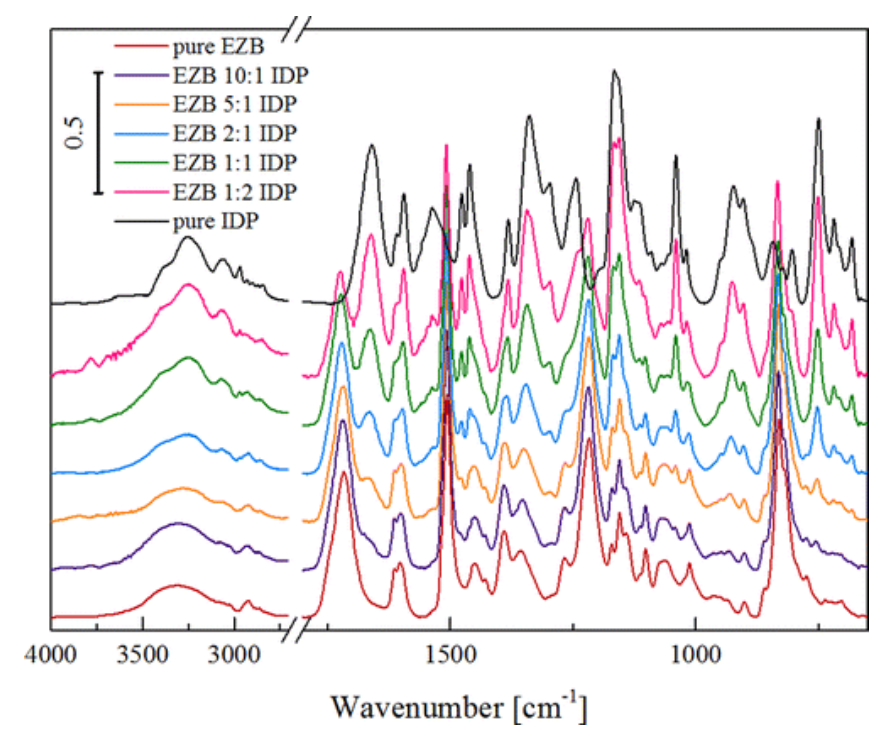

Figure 3. FTIR spectra of binary amorphous mixtures: EZB 10:1 IDP, purple line; EZB 5:1 IDP, orange line; EZB 2:1 IDP, blue line; EZB 1:1 IDP, green line; EZB 1:2 IDP, pink line; and pure EZB and IDP (wine and black lines).

Table 2. Comparison of Absorption Band Positions $\left[\mathrm{cm}^{-1}\right]$ of Examined Systems: Data from FTIR ${ }^{a}$

\begin{tabular}{|c|c|c|c|c|c|c|c|}
\hline assignment & $\begin{array}{l}\text { pure } \\
\text { EZB }\end{array}$ & $\begin{array}{l}\text { EZB } \\
10: 1 \\
\text { IDP }\end{array}$ & $\begin{array}{l}\text { EZB } \\
5: 1 \\
\text { IDP }\end{array}$ & $\begin{array}{l}\text { EZB } \\
2: 1 \\
\text { IDP }\end{array}$ & $\begin{array}{c}\text { EZB } \\
1: 1 \\
\text { IDP }\end{array}$ & $\begin{array}{l}\text { EZB } \\
1: 2 \\
\text { IDP }\end{array}$ & $\begin{array}{l}\text { pure } \\
\text { IDP }\end{array}$ \\
\hline $\begin{array}{c}-\mathrm{C}=\mathrm{O} \\
\mathrm{EZB}\end{array}$ & 1717 & 1718 & 1717 & 1721 & 1723 & 1723 & $\mathrm{~N} / \mathrm{A}$ \\
\hline $\begin{array}{c}-\mathrm{C}=\mathrm{O} \\
\mathrm{IDP}\end{array}$ & N/A & N/A & N/A & 1664 & 1663 & 1662 & 1661 \\
\hline $\begin{array}{c}-\mathrm{C}=\mathrm{C} \\
\text { arom } \\
\text { EZB }\end{array}$ & 1507 & 1508 & 1507 & 1508 & 1508 & 1508 & N/A \\
\hline $\begin{array}{c}-\mathrm{C}-\mathrm{O} \\
\mathrm{EZB}\end{array}$ & 1217 & 1219 & 1218 & 1219 & 1219 & 1220 & N/A \\
\hline $\begin{array}{l}-\mathrm{S}=\mathrm{O} \\
\text { sym IDP }\end{array}$ & N/A & 1156 & 1155 & 1156 & 1156 & 1156 & 1156 \\
\hline \multicolumn{8}{|c|}{${ }^{a}$ N/A: not analyzed. } \\
\hline
\end{tabular}


Molecular Dynamics of Amorphous Mixtures of Ezetimib and Indapamid Drugs above the Glass

\section{Transition}

In this section the effects of IDP drug on the molecular dynamics of EZB in their binary amorphous mixture are presented. To experimentally establish how the molecular mobility of coamorphous EZBIDP composition changes with IDP content, the dielectric loss spectra of five mixtures containing various molar ratios of EZB and IDP were measured by means of broadband dielectric spectroscopy (BDS). In all these measurements, the temperature was increased from 339 to $423 \mathrm{~K}$ in step of $2 \mathrm{~K}$. The representative spectra of binary EZB-IDP mixtures containing $46.9,31.4$, and 8.8 wt \% of IDP drug are shown in Figures $4 a-4 c$, respectively.
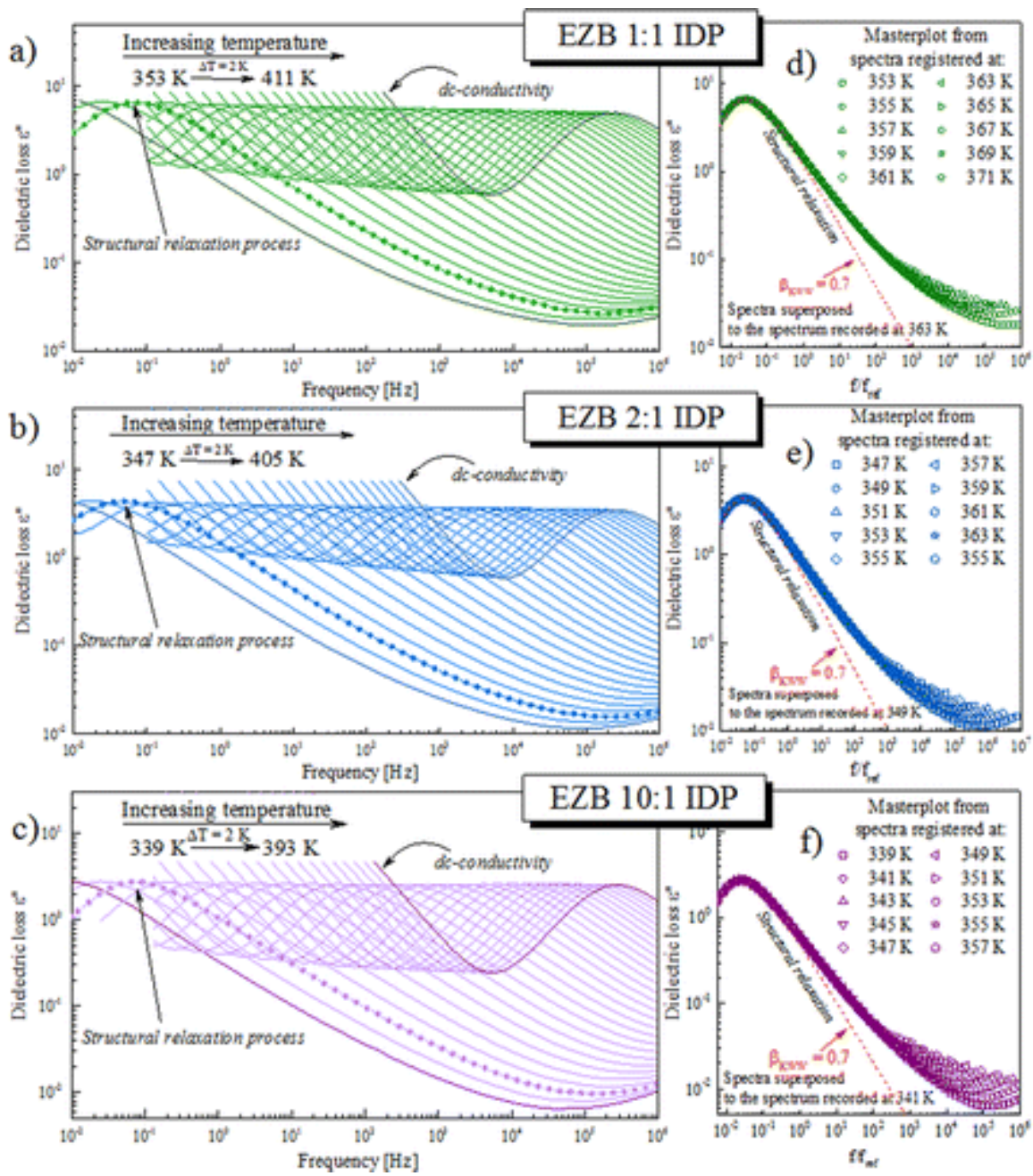

Figure 4. (a-c) Dielectric loss spectra collected above the glass transition temperature of coamorphous EZB-IDP mixtures with molar rations 10:1, 2:1, and 1:1. (d-f) Masterplots for the binary mixtures, EZB 10:1 IDP, EZB 2:1 IDP, EZB 1:1 IDP, that were formed by horizontal shift of arbitrarily chosen spectra to superpose all together with the unshifted spectra at $341 \mathrm{~K}$ (for molar ratio 10:1), $349 \mathrm{~K}$ (for molar ratio $2: 1$ ), and $355 \mathrm{~K}$ (for molar ratio $1: 1$ ). 
The dielectric loss spectra of all examined systems exhibit the same main features: one well-resolved loss peak corresponding to the structural $(\alpha)$ relaxation process as well as dc conductivity. As can be seen, the $\alpha$-relaxation mode moves toward higher frequencies with heating as well as with increasing of IDP content. Additionally, during heating of the examined samples we do not observe any drop in the intensity of structural relaxation peak that indicates an absence of mixture cold crystallization. According to the literature reports, pure amorphous EZB drug measured in similar conditions begins to recrystallize at a temperature at which the maximum of the $\alpha$-relaxation is located at frequency equal to $10^{5} \mathrm{~Hz}$ (what corresponds to $\tau_{\alpha}=1.6 \mu \mathrm{s}$ ).(40) In view of the fact that the mixtures do not begin to crystallize at $\tau_{\alpha} \sim 1.6 \mu \mathrm{s}$, one can conclude that the enhancement of the EZB physical stability in binary EZB-IDP mixture is governed not only by a kinetic factor (i.e., molecular mobility) but also by a thermodynamical factor (i.e., configurational entropy, enthalpy, or Gibbs free energy).

From analysis of dielectric loss spectra the temperature dependences of $\alpha$-relaxation times for all examined coamorphous systems were obtained (see Figure 5a). To determine the values of $\tau_{\alpha}$ as well as dc conductivity at various temperatures, the experimental data have been fitted using the HavrilakNegami (HN) function with the dc conductivity term:(41)

$\varepsilon^{*}(\omega)=\varepsilon_{\infty}+\frac{\Delta \varepsilon}{\left[1+\left(\mathrm{i} \omega \tau_{\mathrm{HN}}\right)^{a}\right]^{b}}+\frac{\sigma_{\mathrm{dc}}}{\varepsilon_{0} \mathrm{i} \omega}(3)$

where $\varepsilon_{\infty}$ is high frequency limit permittivity, $\varepsilon_{0}$ denotes the permittivity of vacuum, $\Delta \varepsilon$ is dielectric strength, $\omega$ is equal to $2 \pi \mathrm{f}, \tau_{\mathrm{HN}}$ is the $\mathrm{HN}$ relaxation time, and $a$ and $b$ represent symmetric and asymmetric broadening of the relaxation peak. On the basis of fit parameters determined above, the values of $\tau_{\alpha}$ were calculated as(42-44)

$\tau_{a}=\tau_{\max }=\tau_{\mathrm{HN}}\left[\sin \left(\frac{\pi a}{2+2 b}\right)\right]^{-1 / a}\left[\sin \left(\frac{\pi a b}{2+2 b}\right)\right]^{1 / a}$

(4)

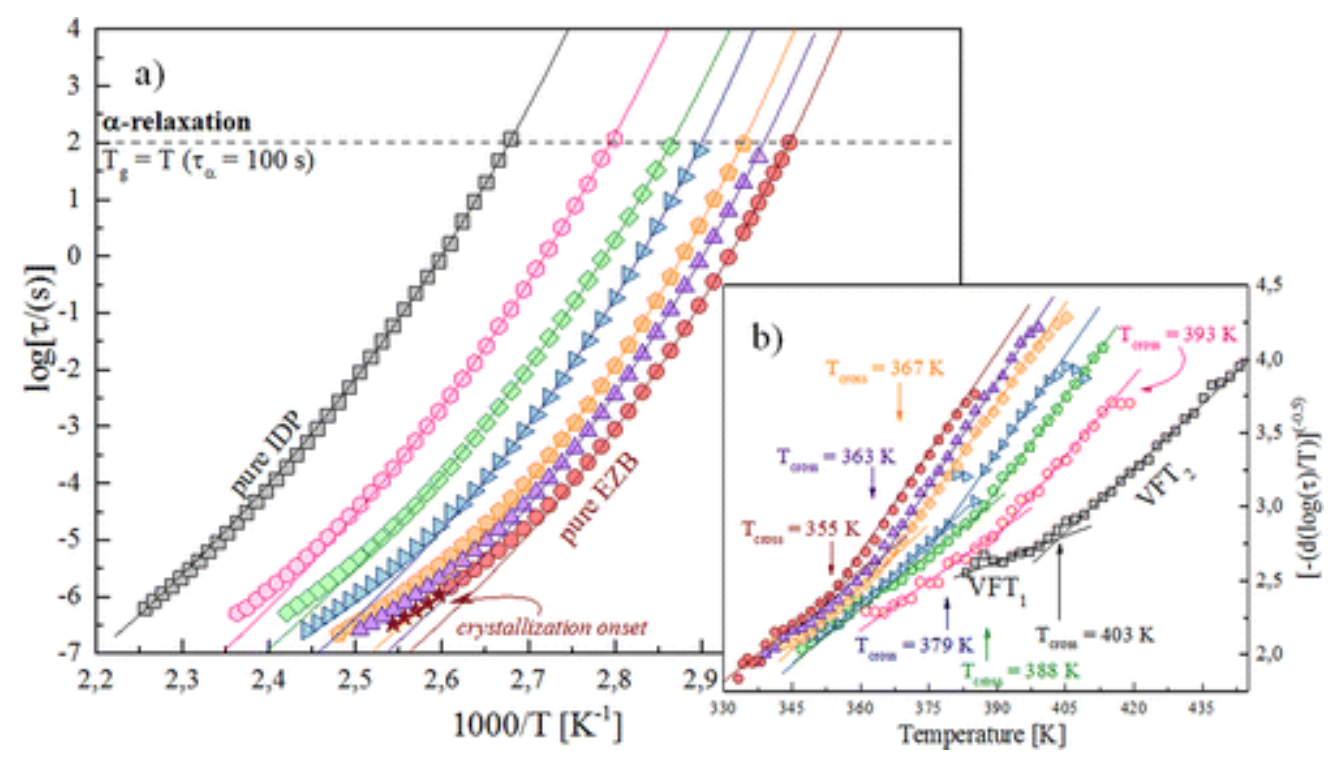


Figure 5. (a) Temperature dependence of the structural relaxation times determined by using the BDS technique for pure amorphous EZB drug (red circles), pure IDP drug (black squares), and their binary mixtures that contain various molar ratios of EZB and IDP: EZB 1:2 IDP (pink hexagons), EZB 1:1 IDP (green diamonds), EZB 2:1 IDP (blue inverted triangles), EZB 5:1 IDP (orange pentagons), and EZB 10:1 IDP (purple triangles). Solid lines (black for pure IDP, pink for EZB 1:2 IDP, green for EZB 1:1 IDP, blue for EZB 1:2 IDP, orange for EZB 5:1 IDP, purple for EZB 10:1 IDP, and red for pure EZB) are the $V_{F T}$ fits. (b) Results of the derivative analysis that was focused on the validity of VFT parameters. The intersection of the two VFT lines in the case of each sample denotes the crossover temperature.

In the supercooled liquid region, the $\tau_{\alpha}(T)$ dependence usually shows non-Arrhenius behavior and follows the Vogel-Fulcher-Tammann (VFT) equation:

$\tau_{a}(T)=\tau_{\infty} \exp \left(\frac{B}{T-T_{0}}\right)(5)$

where $\tau_{\infty}, T_{0}$, and $B$ are fitting parameters.(45-47) Moreover, we found that in the case of pure amorphous samples as well as their mixtures the temperature dependence of structural relaxation time, measured over 8 decades, cannot be described properly by means of a single VFT fit. Thus, to parametrize these data over the entire temperature range, two VFT equations are required. Such behavior is often observed in organic glass-forming materials. $(48,49)$ Good examples of pharmaceuticals that require employing of two VFT equations to describe the $\tau_{\alpha}$ data over wide temperature range are ibuprofen and telmisartan. $(50,51)$

First we analyzed the relaxation data by applying the derivative method proposed by Stickel.(52) Using this method it is possible to identify the temperature range of validity of both VFT equations. The Stickel method requires the use of the operator $\left[d\left(\log \left(\tau_{\alpha}\right)\right) / d T\right]^{-1 / 2}=\left(T-T_{0}\right) B^{-1 / 2}$, which linearized the Vogel-Fulcher-Tammann equation. The results of the derivative analysis are presented in Figure $5 \mathrm{~b}$. As can be seen, two distinct linear regions may be observed for all measured samples, confirming the necessity for use of two sets of VFT parameters to describe properly the $\tau_{\alpha}(T)$ dependences of studied mixtures. The temperature at which the $\mathrm{VFT}_{1}$ and $\mathrm{VFT}_{2}$ intersect ( $\left.T_{\text {cross }}\right)$ as well as all the fitting parameters are collected in Table 3. Additionally, the $\mathrm{VFT}_{1}$ fits are shown in Figure 5a as solid lines.

Table 3. Comparison of the Values of $T_{\mathrm{g}}$ Obtained from TMDSC, $T_{\text {cross, }}$ and $T_{\mathrm{g}}$ Obtained from BDS, Fragility Parameters, and Fitting Parameters from the $\mathrm{VFT}_{1}$ and $\mathrm{VFT}_{2}$ for Pure EZB and IDP Drugs, and Their Binary Amorphous Mixtures at Molar Ratios 10:1, 5:1, 2:1, 1:1, 1:2 


\begin{tabular}{|c|c|c|c|c|c|c|c|c|}
\hline \multirow[b]{2}{*}{ EZB-IDP [molar ratio] } & \multirow[b]{2}{*}{ wt fraction of IDP [\%] } & \multirow[b]{2}{*}{$T_{\text {cross }}[\mathrm{K}]$} & \multicolumn{3}{|c|}{$\mathrm{VFT}_{1}$ and $\mathrm{VFT}_{2}$ params } & \multicolumn{2}{|c|}{$T_{\mathrm{g}}[\mathrm{K}]$} & \multirow[b]{2}{*}{ fragility param $m_{p}$} \\
\hline & & & $\log \tau_{0}$ & $B=D T_{0}$ & $\overline{T_{0}[\mathrm{~K}]}$ & BDS & $\overline{\text { TMDSC }}$ & \\
\hline \multirow[t]{2}{*}{$1: 0$} & 0 & 355 & $-18.5 \pm 0.6$ & $3483.0 \pm 209.8$ & $259.5 \pm 2.4$ & 333.1 & 334.8 & $93.0 \pm 4.3$ \\
\hline & & & $-11.8 \pm 0.1$ & $1130.0 \pm 11.1$ & $301.1 \pm 0.3$ & & & \\
\hline \multirow[t]{2}{*}{ 10:1 } & 8.8 & 363 & $-19.1 \pm 0.5$ & $3767.6 \pm 197.9$ & $258.7 \pm 2.4$ & 336.5 & 337.9 & $92.0 \pm 3.8$ \\
\hline & & & $-11.7 \pm 0.1$ & $1095.7 \pm 10.4$ & $305.9 \pm 0.3$ & & & \\
\hline \multirow[t]{2}{*}{$5: 1$} & 19.9 & 367 & $-19.4 \pm 0.6$ & $3913.5 \pm 273.6$ & $259.7 \pm 3.2$ & 339.2 & 340.3 & $91.0 \pm 4.9$ \\
\hline & & & $-11.9 \pm 0.1$ & $1171.5 \pm 7.1$ & $306.7 \pm 0.2$ & & & \\
\hline \multirow[t]{2}{*}{$2: 1$} & 31.4 & 379 & $-18.5 \pm 0.4$ & $3747.3 \pm 181.1$ & $265.4 \pm 2.2$ & 344.9 & 345.5 & $88.0 \pm 3.2$ \\
\hline & & & $-12.9 \pm 0.4$ & $1581.7 \pm 157.5$ & $301.3 \pm 4.4$ & & & \\
\hline \multirow[t]{2}{*}{$1: 1$} & 46.9 & 388 & $-19.2 \pm 0.3$ & $4553.3 \pm 160.3$ & $255.8 \pm 1.9$ & 349.0 & 351.4 & $80.0 \pm 2.3$ \\
\hline & & & $-12.3 \pm 0.1$ & $1403.2 \pm 24.3$ & $312.6 \pm 0.7$ & & & \\
\hline \multirow[t]{2}{*}{$1: 2$} & 64.8 & 393 & $-20.4 \pm 0.5$ & $5258.5 \pm 266.0$ & $255.8 \pm 3.0$ & 357.8 & 359.2 & $78.0 \pm 2.9$ \\
\hline & & & $-13.7 \pm 0.3$ & $1958.6 \pm 114.7$ & $307.6 \pm 2.8$ & & & \\
\hline \multirow[t]{2}{*}{$0: 1$} & 100 & 403 & $-18.8 \pm 0.7$ & $5072.3 \pm 352.2$ & $267.4 \pm 4.0$ & 373.5 & 375.4 & $73.0 \pm 3.6$ \\
\hline & & & $-15.3 \pm 0.2$ & $2906.5 \pm 87.1$ & $304.1 \pm 1.7$ & & & \\
\hline
\end{tabular}

Since the $\mathrm{VFT}_{1}$ equation describes well the data in the region below the crossover temperature, it was used to estimate the kinetic glass transition temperature of each coamorphous mixture. The $T_{\mathrm{g}}$ values, calculated from commonly known definition $T_{\mathrm{g}}=T\left(\tau_{\alpha}=100 \mathrm{~s}\right)$, are equal to $336.5 \mathrm{~K}, 339.2 \mathrm{~K}, 344.9 \mathrm{~K}$, $349.0 \mathrm{~K}$, and $357.8 \mathrm{~K}$ for mixtures containing $8.8,14.9,31.4,46.9$, and $64.8 \mathrm{wt} \%$ of IDP, respectively. These values are slightly smaller than the $T_{\mathrm{g}}$ obtained by using TMDSC (see inset of Figure 6). This little discrepancy between the kinetic and the calorimetric values of $T_{\mathrm{g}}$ is due to different heating rate used in these two different experiments.

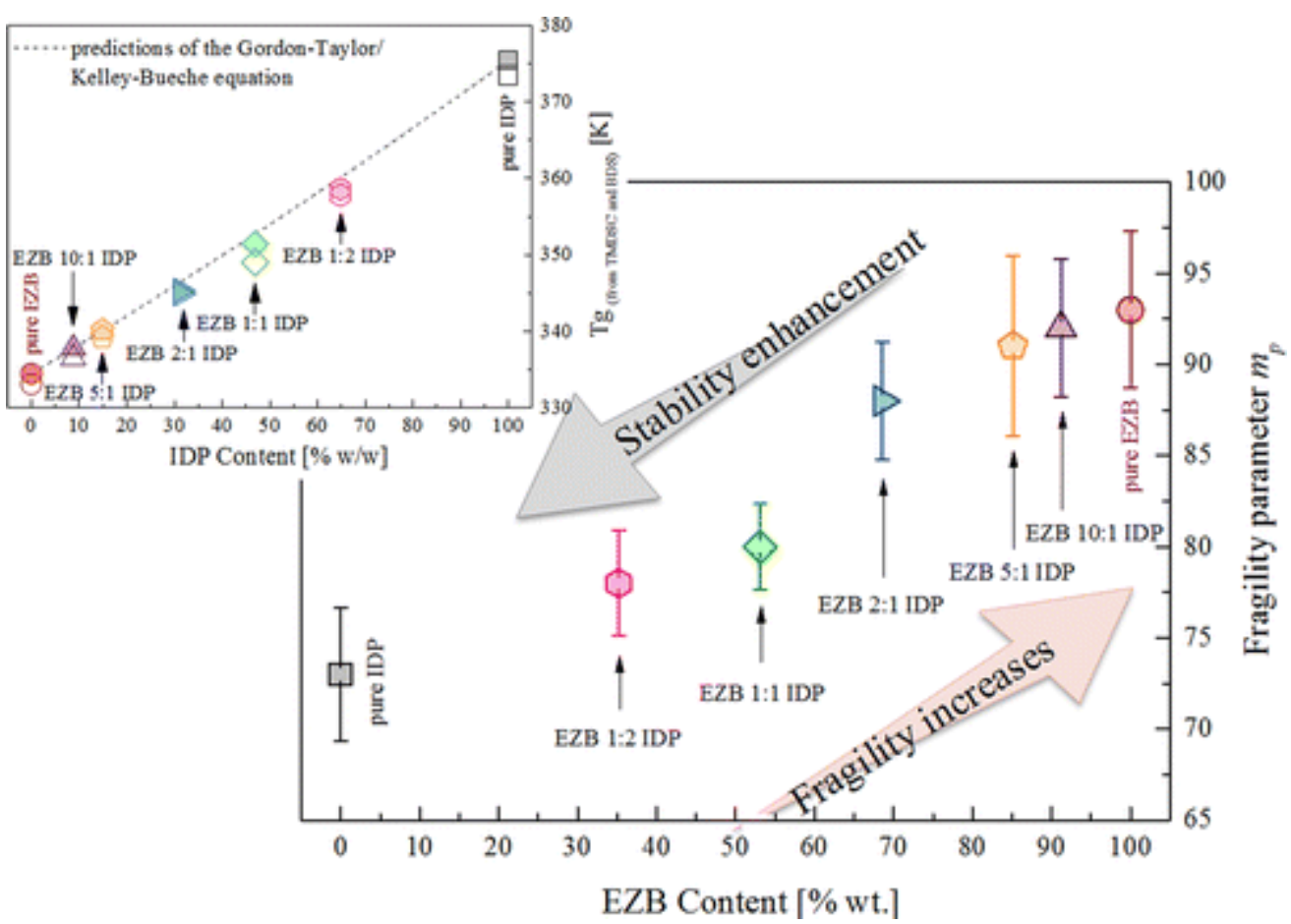

Figure 6. Isobaric fragility parameter estimated from eq 6 plotted versus EZB content. In the inset we compare the glass transition temperatures of coamorphous EZB-IDP mixtures determined by using DSC (filled symbols) and BDS (open symbols) techniques. The dashed line represents the prediction of the Gordon-Taylor/Kelley-Bueche equation. 
Based on the $\mathrm{VFT}_{1}$ fitting parameters as well as on the values of $T_{\mathrm{g}}$, determined previously from dielectric relaxation data, we have estimated the fragility parameter $m_{p}$ (called also steepness index) for all measured systems:(53)

$m_{p}=\left.\frac{\mathrm{d} \log \tau_{\alpha}}{\mathrm{d}\left(T_{\mathrm{g}} / T\right)}\right|_{T=\mathrm{T}_{\mathrm{g}}}=D \frac{T_{0}}{T_{\mathrm{g}}}\left(1-\frac{T_{0}}{T_{\mathrm{g}}}\right)^{-2} \log _{10} \mathrm{e}$

It should be noted that this parameter is of particular interest for the pharmaceutical industry, because it is often used to predict the tendency of disordered materials toward recrystallization.(54) In the literature the fragility parameter is reported to vary from 16 to 200. But, in the case of APIs, the typical $m_{p}$ values range between 60 and 120 . The compounds characterized by a low value of steepness index are classified as strong materials, whereas a large value of $m_{p}$ corresponds to fragile systems. According to the two order parameter (TOP) model proposed by Tanaka, strong materials are expected to be more physically stable than fragile materials.(55) This is because they have stronger frustration against crystallization. This frustration of the system results from the competition between long and short ordering existing in any liquids. Long-range ordering is responsible for nucleation and crystal growth, while short-range ordering is associated with formation of the local favored structures that have no crystallographic symmetry. As illustrated in Figure 6, the fragility parameter decreases continuously with increasing IDP content. This result suggests that the physical stability of the examined mixtures should improve with increasing IDP concentration. Since our measurements do not reveal crystallization of coamorphous compositions containing EZB and IDP, the trend of stability has been checked at elevated temperature $(T=398 \mathrm{~K}$ ) by means of DSC (see Figure 7). These experiments show that the mixture crystallization slows down with increasing IDP content (exothermic peak is shifted to higher times), which proves that the fragility parameter indeed reflects the physical stability of the examined systems.

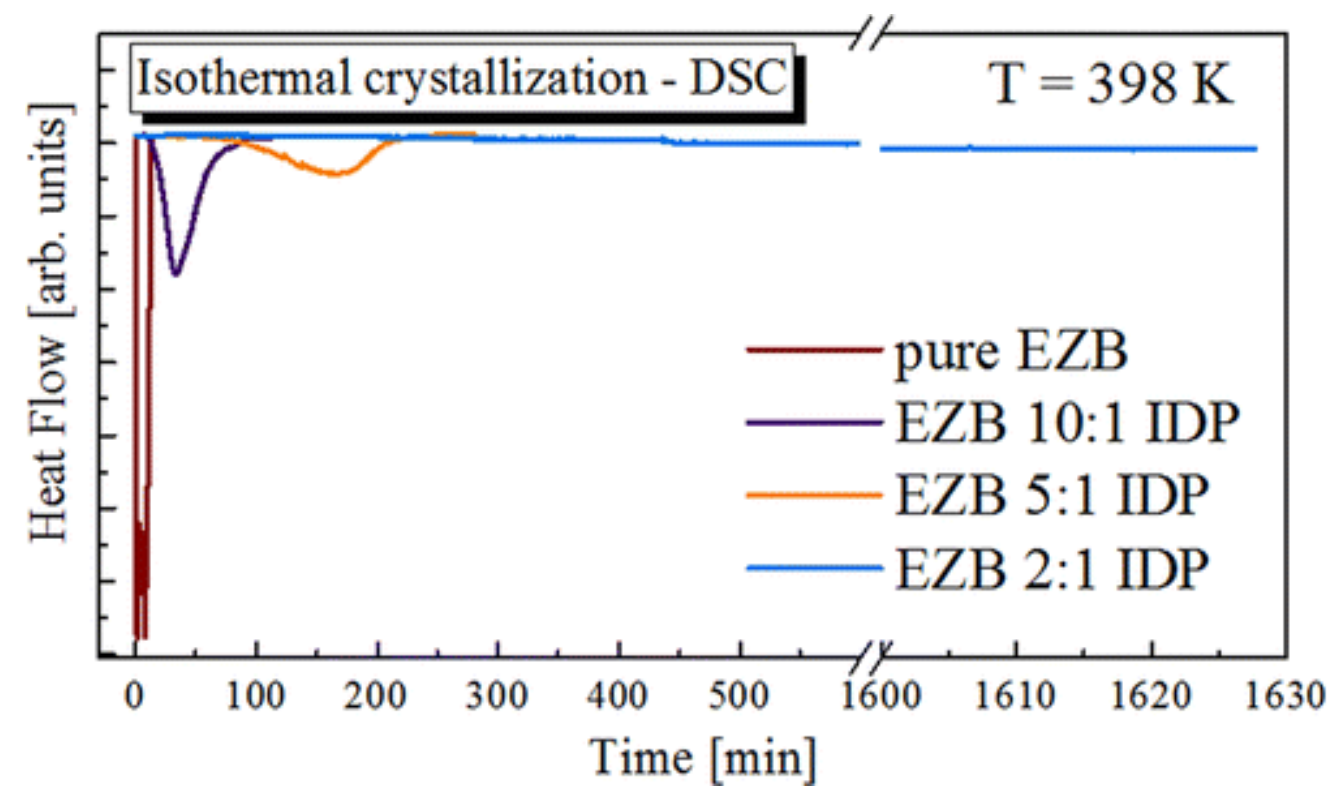


Figure 7. Isothermal crystallization of pure EZB (wine line), EZB 10:1 IDP (purple line), EZB 5:1 IDP (orange line), and EZB 2:1 IDP (blue line) at $398 \mathrm{~K}$.

An alternative measure of the physical stability of amorphous materials is the $\beta_{k w w}$ parameter, which describes the distribution of relaxation times.(56) Shamblin et al. have suggested that, when $\beta_{\mathrm{kww}}$ parameter decreases (i.e., the distribution of relaxation times becomes broader), the tendency of a pharmaceutical to recrystallization should increase. For many drugs this parameter was shown to correctly predict their physical stability. The best examples may be aspirin, ibuprofen, and quinidine.(57)

In order to determine the values of $\beta_{\mathrm{kww}}$ for the measured binary amorphous EZB-IDP mixtures as well as to check whether or not the temperature affects the shape of the $\alpha$-relaxation process, the master curves of individual EZB-IDP mixtures were prepared (see Figure $4 d-f$ ). They were constructed by horizontal shift of arbitrarily chosen spectra to superpose all together with the reference spectrum recorded at $363 \mathrm{~K}, 355 \mathrm{~K}, 349 \mathrm{~K}, 345 \mathrm{~K}$, and $341 \mathrm{~K}$ for mixtures containing 64.8, 46.9, 31.4, 19.9, and $8.8 \mathrm{wt} \%$ of IDP, respectively. As can be seen, the shapes of structural relaxation peaks of each EZBIDP composition do not change with temperature and IDP content. All investigated mixtures have the same value of $\beta_{k w w}$ parameter equal to 0.7 . This value is identical with that for pure amorphous EZB drug. This invariability of the $\beta_{\mathrm{kww}}$ suggests that the mentioned parameter does not correlate with the physical stability of the herein studied coamorphous mixtures.

\section{Long-Term Physical Stability Studies of EZB-IDP Coamorphous Mixtures}

As it was indicated by both BDS and DSC data, the coamorphous mixtures containing EZB and IDP drugs are characterized by greater physical stability than the pure EZB. Naturally, the questions arise: what is the minimal amount of IDP guaranteeing appropriate physical stability of the amorphous EZB? and consequently, how long we can safely store these compositions at room temperature? In order to answer these questions we have performed time dependent isothermal XRD studies for all investigated binary mixtures. During this experiment samples were kept at constant temperature equal to $297 \mathrm{~K}$ and under quasi-constant humidity conditions $\mathrm{RH}=25 \%$. On the basis of the obtained $X$-ray diffraction patterns we determined the relative degree of crystallization $D_{c}$ for all measured samples. The values of $D_{c}$ for each sample were determined as a ratio: $A_{p} / A_{c}$, where $A_{p}$ and $A_{c}$ are areas under the sharp XRD peaks of the partly crystalline sample and the crystalline reference sample, respectively. The values of $D_{c}$ plotted versus time of storage as well as the representative XRD patterns are presented in the Figure 8. 


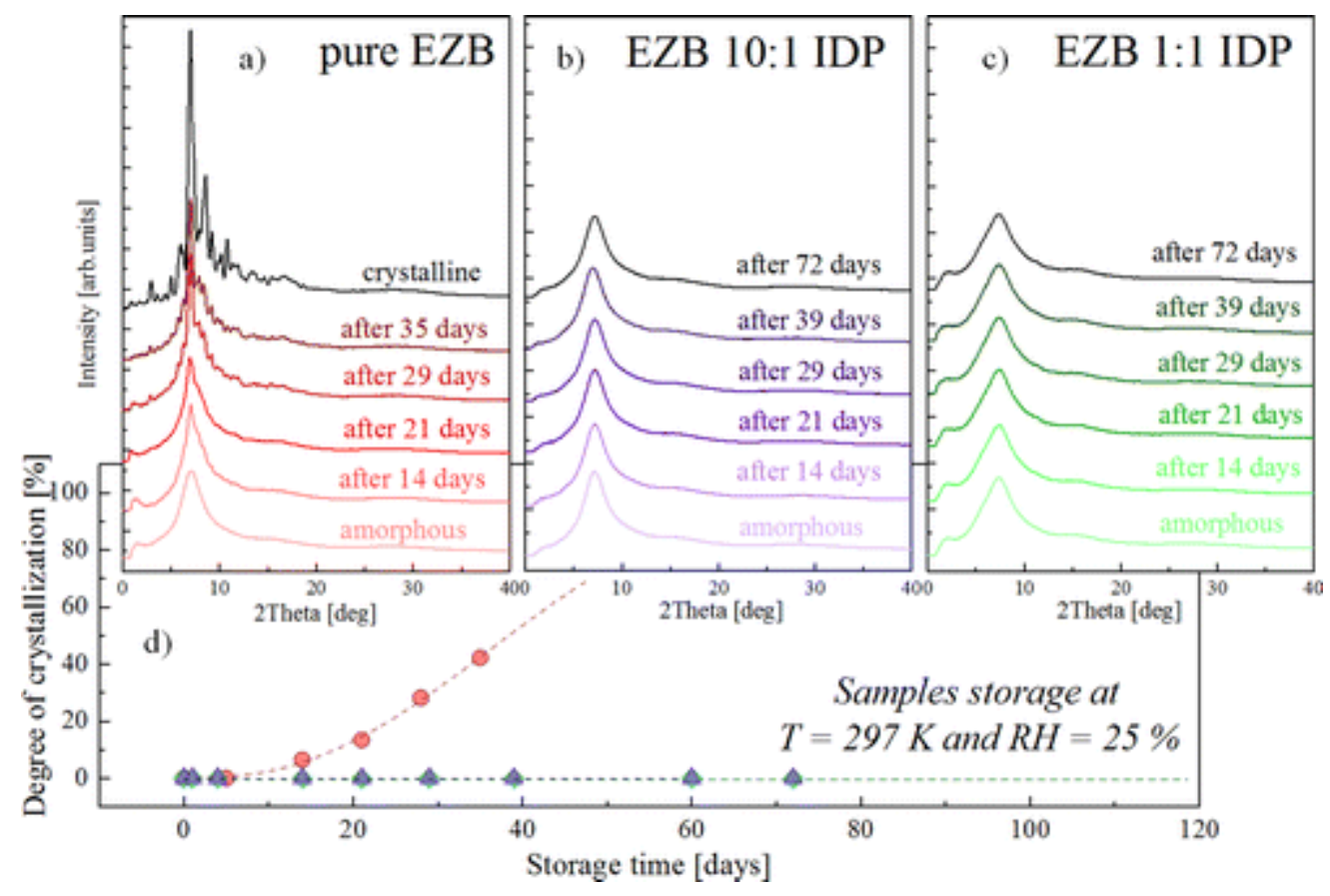

Figure 8. $(a-c)$ The representative X-ray diffraction patterns for pure EZB, EZB 10:1 IDP, and EZB 1:1 IDP measured after specified time period. (d) The relative degree of crystallization $D_{\mathrm{c}}$ of amorphous EZB, EZB 10:1 IDP, and EZB 1:1 IDP as a function of storage time at $T=297 \mathrm{~K}$ and $\mathrm{RH}=25 \%$. Data for pure EZB were taken from ref 40.

As can be seen, the X-ray diffraction patterns for the initially amorphous compounds are characterized by broad amorphous halos which confirm that in the investigated samples there were no threedimensional long-range ordered structures. This finding indicates that the tested systems just after preparation were fully amorphous. After 21 days of storage small and sharp crystalline peaks might be observed only on the EZB XRD pattern, proving that a small portion of amorphous EZB recrystallized $\left(D_{c}=15 \%\right)$. Others systems, after the same period of time, remained unchanged, and their degree of crystallization was equal to zero. Interestingly, even after 72 days, all investigated EZB-IDP mixtures were still physically stable, i.e., we did not observe any Bragg peaks in XRD patterns.

The XRD studies show that mixtures containing EZB and IDP are characterized by high physical stability. Even a small amount of IDP drug (8.8 wt \%) is able to suppress the EZB's recrystallization for at least 72 days, when the mixture is stored at $297 \mathrm{~K}$. It should be noted that, from a medical point of view, the best seems to be EZB-IDP mixture containing 11.1 to $33.3 \mathrm{wt} \%$ of IDP. Since these values are higher than $8.8 \mathrm{wt} \%$ of IDP, it is obvious that such binary compositions will be very stable. 


\section{Conclusions}

In this article the coamorphous binary mixture of ezetimib and indapamide was investigated by using differential scanning calorimetry, broadband dielectric spectroscopy, and X-ray diffraction. We found that the simple quench cooling method can be applied for the production of homogeneous composition of these two pharmaceuticals. Thermal analysis of mixtures characterized by various molar ratios of EZB and IDP indicated that the glass transition temperature $\left(T_{\mathrm{g}}\right)$ rises with increasing IDP content in accordance with the Gordon-Taylor equation. This result suggests that improvement of the physical stability of highly unstable amorphous EZB drug in binary mixture is mainly caused by an antiplasticizing effect exerted by IDP.

The effect of IDP on the molecular dynamics of amorphous EZB in their coamorphous compositions was investigated over a broad temperature and frequency range by using dielectric spectroscopy. These experiments have shown that, besides an antiplasticizing effect, an additional factor is also responsible for the physical stability improvement of the measured mixtures. Based on dielectric data we determined the $m_{p}$ and $\beta_{k w w}$ parameters that characterize the structural relaxation process. These parameters are generally considered as a measure of the physical stability of systems in disordered state. A low value of fragility parameter and a narrow $\alpha$-relaxation peak (i.e., high value of $\beta_{k w w}$ ) correspond to high stability. Our studies have shown that the $m_{p}$ parameter indeed reflects the tendency to recrystallization of coamorphous binary EZB-IDP mixtures. However, such a correlation was not observed in the case of $\beta_{\mathrm{kww}}$. The shape of the structural relaxation loss peak is fixed for mixtures with different concentrations of EZB-IDP drugs. The value of $\beta_{\mathrm{kww}}$ parameter for all tested binary systems as well as for pure amorphous EZB is equal to 0.7. Using XRD techniques we also examined the long-term physical stability of binary mixtures that contain EZB and IDP drugs. These measurements have proven that even a small amount of IDP drug ( $8.8 \mathrm{wt} \%)$ may significantly suppress the devitrification of amorphous EZB drug: after 60 days the tested mixture was fully amorphous. As a consequence the coamorphous binary ezetimib-indapamid system is a very promising candidate for new formulations intended for combined therapy. Apart from the medical and economic benefits of using these drugs together in amorphous forms, such a binary composition provides high physical stability that is essential for further commercial application.

The authors declare no competing financial interest.

\section{Acknowledgment}

The authors Z.W., K.G., and M.P. are grateful for the financial support of the National Science Centre within the Opus3 project (Grant No. DEC-2012/05/B/NZ7/03233). The authors wishes to express their 
thanks for the critical reading of the manuscript by E. Mc Court, Queen's University of Belfast. L.T. is funded by Science Foundation Ireland under grant No. 12/RC/2275 (Synthesis and Solid State Pharmaceuticals Centre).

\section{References}

1. Rasenack, N.; Müller, B. W. Poorly water-soluble drugs for oral delivery: a challenge for pharmaceutical development. Part I: Physicochemical and biopharmaceutical background/strategies in pharmaceutical development Pharm. Ind. 2005, 67 (3) 323- 326

2. Lipinski, C. Poor aqueous solubility - an industry wide problem in drug delivery Am. Pharm. Rev. $2002,5,82-85$

3. Bhardwaj, S. P.; Suryanarayanan, R. Molecular mobility as an effective predictor of the physical stability of amorphous trehalose Mol. Pharmaceutics 2012, 9 (11) 3209- 3217

4. Wojnarowska, Z.; Grzybowska, K.; Hawelek, L.; Dulski, M.; Wrzalik, R.; Gruszka, I.; Paluch, M.; Pienkowska, K.; Sawicki, W.; Bujak, P.; Paluch, K. J.; Tajber, L.; Markowski, J. Molecular Dynamics, Physical Stability and Solubility Advantage from Amorphous Indapamide Drug Mol. Pharmaceutics 2013,10 (10) 3612-3627

5. Bhugra, C.; Pikal, M. Role of thermodynamic, molecular, and kinetic factor in crystallization from amorphous state J. Pharm. Sci. 2008, 97, 1329-1349

6. Yoshioka, M.; Hancock, B. C.; Zografi, G. Crystallization of indomethacin from the amorphous state below and above its glass transition temperature J. Pharm. Sci. 1994, 83, 1700

7. Kothari, K.; Ragoonanan, V.; Suryanarayanan, R. Influence of Molecular Mobility on the Physical Stability of Amorphous Pharmaceuticals in the Supercooled and Glassy States Mol. Pharmaceutics $2014,11,3048-3055$

8. Priemel, P. A.; Laitinen, R.; Barthold, S.; Grohganz, H.; Lehto, V.-P.; Rades, T.; Strachan, C. J. Inhibition of surface crystallisation of amorphous indomethacin particles in physical drug-polymer mixtures Int. J. Pharm. 2013, 456, 301- 306

9. Van Eerdenbrugh, B.; Taylor, L. S. Small Scale Screening To Determine the Ability of Different Polymers To Inhibit Drug Crystallization upon Rapid Solvent Evaporation Mol. Pharmaceutics 2010, 7 (4) $1328-1337$

10. Taylor, T. S.; Zografi, G. Pharm. Res. 1997, 14 (12) 1691- 1698 
11. Miyazaki, T.; Yoshioka, S.; Aso, Y. Physical Stability of Amorphous Acetanilide Derivatives Improved by Polymer Excipients Chem. Pharm. Bull. 2006, 54 (8) 1207-1210

12. Matsumoto, T.; Zografi, G. Physical Properties of Solid Molecular Dispersions of Indomethacin with Poly(Vinylpyrrolidone) and Poly- (Vinylpyrrolidone-Co-Vinyl-Acetate) in Relation to Indomethacin Crystallization Pharm. Res. 1999, 16 (11) 1722-1728

13. Kothari, K.; Ragoonanan, V.; Suryanarayanan, R. The Role of Drug-Polymer Hydrogen Bonding Interactions on the Molecular Mobility and Physical Stability of Nifedipine Solid Dispersions Mol. Pharmaceutics 2015, 12, 162-170

14. Gupta, P.; Thilagavathi, R.; Chakraborti, A. K.; Bansal, A. K. Role of Molecular Interaction in Stability of Celecoxib-PVP Amorphous Systems Mol. Pharmaceutics 2005, 2 (5) 384- 391

15. Laitinen, R.; Lobmann, K.; Strachan, C. J.; Grohganz, H.; Rades, T. Emerging trends in the stabilization of amorphous drugs Int. J. Pharm. 2013, 453, 65- 79

16. Serajuddin, A. T. Solid dispersion of poorly water-soluble drugs: early promises, subsequent problems, and recent breakthroughs J. Pharm. Sci. 1999, 88 (10) 1058- 66

17. Shrivastava, A. R.; Ursekar, B.; Kapadia, C. J. Design, optimization, preparation and evaluation of dispersion granules of valsartan and formulation into tablets Curr. Drug Delivery 2009, 6 (1) 28- 37

18. Löbmann, K.; Strachan, C.; Grohganz, H.; Rades, T.; Korhonen, O.; Laitinen, R. Co-amorphous simvastatin and glipizide combinations show improved physical stability without evidence of intermolecular interactions Eur. J. Pharm. Biopharm. 2012, 81 (1) 159-69

19. Chieng, N.; Aaltonen, J.; Saville, D.; Rades, T. Physical characterization and stability of amorphous indomethacin and ranitidine hydrochloride binary systems prepared by mechanical activation Eur. J. Pharm. Biopharm. 2009, 71 (1) 47- 54

20. Grzybowska, K.; Paluch, M.; Wlodarczyk, P.; Grzybowski, A.; Kaminski, K.; Hawelek, L.; Zakowiecki, D.; Kasprzycka, A.; Jankowska - Sumara, I. Enhancement of amorphous celecoxib stability by mixing it with octaacetylmaltose: the molecular dynamics study Mol. Pharmaceutics 2012, 9 (4) 894- 904

21. Kaminska, E.; Adrjanowicz, K.; Tarnacka, M.; Kolodziejczyk, K.; Dulski, M.; Mapesa, E. U.; Zakowiecki, D.; Hawelek, L.; Kaczmarczyk-Sedlak, I.; Kaminski, K. Impact of inter- and intramolecular interactions on the physical stability of indomethacin dispersed in acetylated saccharides Mol. Pharmaceutics 2014, 11 (8) 2935- 2947 
22. Yamamura, S.; Gotoh, H.; Sakamoto, Y.; Momose, Y. Physicochemical properties of amorphous salt of cimetidine and diflunisal system Int. J. Pharm. 2002, 241 (2) 213- 21

23. Alles $\varnothing$, M.; Chieng, M.; Rehder, S.; Rantanen, J.; Rades, T.; Aaltonen, J. Enhanced dissolution rate and synchronized release of drugs in binary systems through formulation: Amorphous naproxencimetidine mixtures prepared by mechanical activation J. Controlled Release 2009, 136, 45- 53

24. Löbmann, K.; Laitinen, R.; Grohganz, H.; Gordon, C.; Strachan, C.; Rades, T. Coamorphous Drug Systems: Enhanced Physical Stability and Dissolution Rate of Indomethacin and Naproxen Mol. Pharmaceutics 2011, 8, 1919- 1928

25. Wong, N. D.; Lopez, V.; Tang, S.; Williams, G. R. Prevalence, treatment, and control of combined hypertension and hypercholesterolemia in the United States Am. J. Cardiol. 2006, 98 (2) 204- 208

26. Eaton, C. B.; Feldman, H. A.; Assaf, A. R.; McPhillips, J. B.; Hume, A. L.; Lasater, T. M.; Levinson, P.; Carleton, P. A. Prevalence of hypertension, dyslipidemia, and dyslipidemic hypertension J. Fam. Pract. 1994, 38, 17- 23

27. Johnson, M. L.; Pietz, K.; Battleman, D. S.; Beyth, R. J. Prevalence of comorbid hypertension and dyslipidemia and associated cardiovascular disease Am. J. Managed Care 2004, 10, 926- 932

28. Yaro, P.; He, X.; Liu, W.; Xun, M.; Ma, Y.; Li, Z.; Shi, X. In vitro-in vivo correlations for three different commercial immediate-release indapamide tablets Drug Dev. Ind. Pharm. 2014, 40 (12) $1670-1676$

29. Bali, V.; Ali, M.; Ali, J. Study of surfactant combinations and development of a novel nanoemulsion for minimising variations in bioavailability of ezetimibe Colloids Surf., B 2010, 76 (2) $410-420$

30. Knopp, R. H.; Gitter, H.; Truitt, T.; Bays, H.; Manion, C. V.; Lipka, L. J.; LeBeaut, A. P.; Suresh, R.; Yang, B.; Veltri, E. P. Effects of ezetimibe, a new cholesterol absorption inhibitor, on plasma lipids in patients with primary hypercholesterolemia Eur. Heart J. 2003, 24 (8) 729-741

31. Leonetti, G. Clinical Positioning of Indapamide Sustained Release $1.5 \mathrm{mg}$ in Management Protocols for Hypertension Drugs 2000, 59 (2) 27- 38

32. Adrjanowicz, K.; Wojnarowska, Z.; Grzybowska, K.; Hawelek, L.; Kaminski, K.; Paluch, M.; Kasprzycka, A.; Walczak, K. Molecular dynamics and crystallization phenomenon of supercooled and glassy DNA and RNA nucleosides: $\beta$-adenosine, $\beta$-thymidine, and $\beta$-uridine Phys. Rev. E 2011, 84, 051507 
33. Kolodziejczyk, K.; Paluch, M.; Grzybowska, K.; Grzybowski, A.; Wojnarowska, Z.; Hawelek, L.; Ziolo, J. D. Relaxation Dynamics and Crystallization Study of Sildenafil in the Liquid and Glassy States Mol. Pharmaceutics 2013, 10 (6) 2270-2282

34. Bhardwaj, S. P.; Arora, K. K.; Kwong, E.; Templeton, A.; Clas, S.-D.; Suryanarayanan, R. Correlation between Molecular Mobility and Physical Stability of Amorphous Itraconazole Mol. Pharmaceutics $2013,10,694-700$

35. Baird, J. A.; Taylor, L. S. Evaluation of amorphous solid dispersion properties using thermal analysis techniques Adv. Drug Delivery Rev. 2012, 64 (5) 396- 421

36. Van den Mooter, G.; Wuyts, M.; Blaton, N.; Busson, R.; Grobet, P.; Augustijns, P.; Kinget, R. Physical stabilisation of amorphous ketoconazole in solid dispersions with polyvinylpyrrolidone K25 Eur. J. Pharm. Sci. 2001, 12 (3) 261-269

37. Gordon, M.; Taylor, J. S. Ideal copolymers and the 2 nd-order transitions of synthetic rubbers 1. Non-crystalline copolymers J. Appl. Chem. 1952, 2, 493- 500

38. Kelley, F. N.; Bueche, F. Viscosity and glass temperature relations for polymer diluent systems J. Polym. Sci. 1961, 50, 549- 556

39. Couchman, P. R.; Karasz, F. E. A classical thermodynamic discussion on the effect of composition on glass-transition temperatures Macromolecules 1978, 11, 117- 119

40. Knapik, J.; Wojnarowska, Z.; Grzybowska, K.; Hawelek, L.; Sawicki, W.; Wlodarski, K.; Markowski, J.; Paluch, M. Physical Stability of the Amorphous Anticholesterol Agent (Ezetimibe): The Role of Molecular Mobility Mol. Pharmaceutics 2014, 11, 4280- 4290

41. Kremer, F.; Schönhals, A., Eds. Broadband Dielectric Spectroscopy; Springer: Berlin, 2003.

42. Wojnarowska, Z.; Grzybowska, K.; Adrjanowicz, K.; Kaminski, K.; Paluch, M.; Hawelek, L.; Wrzalik, R.; Dulski, M.; Sawicki, W.; Mazgalski, J.; Tukalska, A.; Bieg, T. Study of the Amorphous Glibenclamide Drug: Analysis of the Molecular Dynamics of Quenched and Cryomilled Material Mol. Pharmaceutics 2010, 7, 1692-1707

43. Wojnarowska, Z.; Wlodarczyk, P.; Kaminski, K.; Grzybowska, K.; Hawelek, L.; Paluch, M. On the Kinetics of Tautomerism in Drugs - New Application of Broadband Dielectric Spectroscopy J. Chem. Phys. 2010, 133, 094507

44. Floudas, G.; Paluch, M.; Grzybowski, A.; Ngai, K. Molecular Dynamics of Glass-Forming Systems: Effects of Pressure; Springer-Verlag: Berlin Heidelberg, 2011. 
45. Tammann, G.; Hesse, W. Die Abhängigkeit der Viscosität von der Temperatur bie unterkühlten Flüssigkeiten Z. Anorg. Allg. Chem. 1926, 156, 245- 257

46. Fulcher, G. S. Analysis of Recent Measurements of the Viscosity of Glasses J. Am. Ceram. Soc. $1925,8,339-355$

47. Vogel, H. Das Temperaturabhangigkeitgesetz der Viskosität von Flüssigkeiten J. Phys. Z. 1921, $22,645-646$

48. Casalini, R.; Paluch, M.; Roland, C. M. The dynamics crossover region in phenol- and cresolphthalein-dimethylethers under different conditions of pressure and temperature J. Phys.: Condens. Matter 2003, 15, S859-S867

49. Casalini, R.; Paluch, M.; Roland, C. M. Dynamic crossover in supercooled liquids induced by high pressure J. Chem. Phys. 2003, 118 (13) 5701- 5703

50. Bras, A. R.; Noronha, J. P.; Antunes, A. M. M.; Cardoso, M. M.; Schonhals, A.; Affouard, F.; Dionisio, M.; Correia, N. T. Molecular Motions in Amorphous Ibuprofen As Studied by Broadband Dielectric Spectroscopy J. Phys. Chem. B 2008, 112, 11087- 11099

51. Adrjanowicz, K.; Wojnarowska, Z.; Wlodarczyk, P.; Kaminski, K.; Paluch, M.; Mazgalski, J. Molecular mobility in liquid and glassy states of Telmisartan (TEL) studied by Broadband Dielectric Spectroscopy Eur. J. Pharm. Sci. 2009, 38, 395

52. Stickel, F.; Fischer, E. W.; Richert, R. Dynamics of glass-forming liquids. I. Temperaturederivative analysis of dielectric relaxation data J. Chem. Phys. 1995, 102, 6251

53. Bohmer, R.; Ngai, K. L.; Angell, C. A.; Plazek, D. J. Nonexponential relaxations in strong and fragile glass formers J. Chem. Phys. 1993, 99, 4201

54. Grzybowska, K.; Paluch, M.; Grzybowski, A.; Wojnarowska, Z.; Hawelek, L.; Kolodziejczyk, K.; Ngai, K. L. Molecular dynamics and physical stability of amorphous anti-inflammatory drug: celecoxib J. Phys. Chem. B 2010, 114, 12792-12801

55. Tanaka, H. Relationship among glass-forming ability, fragility, and short-range bond ordering of liquids J. Non-Cryst. Solids 2005, 351, 678-690

56. Shamblin, S. L.; Tang, X.; Chang, L.; Hancock, B. C.; Pikal, M. J. Characterization of the time scales of molecular motion in pharmaceutically important glasses J. Phys. Chem. B 1999, 103, 4113- 4121

57. Goodwin, A. A.; Mercer, F. W.; McKenzie, M. T. Thermal Behavior of Fluorinated Aromatic Polyethers and Poly(ether ketone)s Macromolecules 1997, 30, 2767- 2774 